\title{
AMBIGÜIDADES NA CONSTRUÇÃO DE UM "GÊNIO BRASILEIRO"
}

\author{
PINTURA NÃO É SÓ BELEZA: A CRÍTICA DE ARTE DE MÁRIO DE ANDRADE, \\ de Tadeu Chiarelli. Florianópolis: Letras Contemporâneas, 2007, 325 p.
}

ICLEIA BORSA CATTANI

Uma importante lacuna nos estudos sobre a modernidade e o modernismo no Brasil acaba de ser preenchida com a publicação do livro de Tadeu Chiarelli, que aprofunda, de forma original, a análise das idéias estéticas e da crítica de arte do período.

Modernidade, modernismo, vanguardas e retorno à ordem são conceitos que, quando pensados a partir da história da arte brasileira, formam uma totalidade complexa. Em relação aos países europeus, eles possuem diferenças claras e correspondem à análise de fenômenos igualmente distintos. Pode-se dizer que, naqueles países, a modernidade na arte correspondeu à sua ação dentro da nova realidade urbana e industrial, propondo a constituição de sistemas de signos inovadores, que foram progressivamente rompendo com a arte do passado e com a ideologia burguesa dominante desde meados do século XIX. As vanguardas dos anos 1900-10 concretizaram as rupturas e as novas proposições radicais que constituíram essa modernidade: as pesquisas iniciais de Picasso e Braque, o futurismo, o expressionismo, as abstrações, o dadá e o surrealismo.

O retorno à ordem converteu até certo ponto, no período entreguerras (mas com manifestações desde 1910), o experimentalismo e a abertura de campos realizados pelas vanguardas em conjuntos mais ou menos rígidos de normas, regras e leis que deveriam nortear a produção artística. Com isso, o espaço moderno de rupturas sofreu, conforme os momentos e segundo os países, desde "neutralizações mascaradas" até endurecimentos dogmáticos. Em alguns países, movimentos que constituíram esse retorno à ordem chegaram a unirse, antes da II Guerra Mundial, a regimes totalitários, como foi o caso na Alemanha e na Itália. A crença na modernidade de muitos dos primeiros artistas que constituíram as vanguardas foi consideravelmente 
abalada pelo grande massacre da I Guerra Mundial e pelas turbulências de toda ordem que se seguiram: repressões violentas ao espírito derrotista que se instalou nos exércitos de vários países, desilusão quando se constatou que as insurreições que visavam destruir o mundo burguês não afetaram a ordem vigente (exceção feita à revolução soviética). Na arte, as revoltas foram bem caracterizadas pelo movimento dadá. O retorno à ordem constituiu uma reação a essa situação, associando-se ao movimento similar que ocorreu na vida social e política daquelas nações e que culminou nas vitórias da extrema direita. Mas ele foi marcado por ambigüidades. Em um primeiro momento, confundiu-se, nas idéias propugnadas por várias publicações e grupos artísticos a elas vinculados, com a aparente defesa de pesquisas de ruptura do início do cubismo, do futurismo, da pintura metafísica, do expressionismo. Com o tempo, os aspectos normativos, dogmáticos, e até mesmo xenófobos e nacionalistas, foram se destacando: inicialmente, nos termos de uma chamada à ordem, estética, moral e política; a seguir, como o retorno à ordem definido pela tradição, por princípios artísticos tidos como eternos e imutáveis, concretizados por estilos anteriores às inovações modernas, como a figuração realista-naturalista do século XIX.

Os movimentos buscavam negar tudo o que tentou desfazer a ordem vigente, o internacionalismo, a abertura ao novo e, de modo geral, o potencial de ruptura das vanguardas. As publicações procuravam neutralizá-las, atacando-as e mostrando-as como produto de um momento anárquico, de procura cega de caminhos, ao qual se sucedia um momento regenerador. Foi o que aconteceu, com muita clareza, nas publicações de André Lhote e Albert Gleizes.

O livro Do cubismo, escrito em 1912 por Gleizes e Jean Metzinger, apresenta-se como um marco inicial na procura de diretrizes eternas que regeriam os movimentos modernos. As publicações de Lhote e Roger Bissière também foram fundamentais para a definição do cubismo, desde 1917, apresentando-o como um campo de pesquisas delimitado por objetivos estritos que visam alcançar as leis da pintura. Constata-se que não foram os artistas de primeira grandeza do momento inicial que levaram a cabo essa delimitação, como Picasso e Braque, mas seguidores de segunda ordem (com os quais, coincidentemente, Tarsila de Amaral estudou e aprendeu o "serviço militar do cubismo" na sua bem conhecida declaração, exceção feita a Fernand Léger, também seu professor). Lhote, em um texto de 1921, chegou a declarar que as artes plásticas tinham voltado a ser "diretoras de consciência"... (conferência intitulada, significativamente, "Reabilitação das artes plásticas", publicada no livro Tradição e cubismo, Paris, La Cible, 1927).

Esse resgate de uma tradição, a procura das "leis eternas" e dos valores da pintura marcaram diversas publicações e movimentos. Sem se 
[1] Suas leituras são estudadas em várias publicações, como no livro de Maria Helena Grembecki, Mário de Andrade e L'Esprit Nouveau, São Paulo: Instituto de Estudos Brasileiros da USP, 1969. situarem forçosamente como defensores de uma plástica tradicional, eles propugnavam, no entanto, o amálgama das experiências mais inovadoras com a tradição e com a defesa de formas de representação figurativas. Nessa linha estavam a revista L'Esprit Nouveau, publicada de 1920 a 1924 e dirigida por Amédée Ozenfant e Charles-Edouard Jeanneret (o futuro arquiteto Le Corbusier). Se essa revista defendia o cubismo, seus articulistas procuravam de modo geral, sobretudo os editores, as linhas mestras desse movimento, acabando por definir os princípios do purismo, princípio de construção e de ordem plásticas.A revista italiana Valori Plastici (1918-21), por sua vez, defendia e propagava, sobretudo no início, a pintura metafísica, tentando simultaneamente encontrar, no entanto, em especial em seus elementos plásticos, uma ordem na arte, que se confundia com a ordem moral e política. Entre seus redatores estavam Carlo Carrà, Giorgio de Chirico e Mario Sironi, que comporiam o grupo Novecento a partir de 1922. Esse grupo já representaria nova etapa do retorno à ordem, marcado em seus escritos teóricos por grande tendência ao conservadorismo, progressivamente acentuado, salientando os valores da nacionalidade, que deveriam manifestar-se cada vez mais na prática artística pelo recurso aos grandes artistas do passado. As posições de vários membros do grupo aproximaram-se cada vez mais dos "valores" fascistas, com seu complemento de xenofobia em relação a artistas e a estilos de outros países, levando, assim, a extremos a ordem propugnada por Valori Plastici .

No Brasil, a arte modernista constituiu-se no entrecruzamento desses movimentos antagônicos, criando uma situação complexa na qual produções com elementos de cor local, como princípios de volumetria e profundidade perspectiva e outros componentes da arte anterior aos anos 1850 , desempenharam papel de vanguarda. Elas romperam com uma figuração definida ainda em sua grande maioria pelos princípios acadêmicos, tentando definir, em relação às novas condições de industrialização, crescimento urbano e relações sociais da cidade, uma modernidade possivel. No contexto local, essas produções contraditórias desempenharam efetivamente um papel de vanguarda e foram percebidas como tal.

O papel de Mário de Andrade foi fundamental nesse contexto. Seu pensamento foi formatado em grande parte pelas leituras dos textos publicados nos periódicos e em outros veículos pelos membros dos grupos mencionados acima, como assinala Chiarelli. O peso global que tiveram as idéias veiculadas por essas publicações na constituição de uma estética "moderna" para o Brasil é questão abordada em vários pontos de Pintura não é só beleza. Mário possuía as coleções completas das revistas citadas, bem como número importante de livros europeus $^{1}$. É digno de nota que, no manifesto publicado no primeiro número da revista Klaxon, apenas três meses após o evento da Semana 
de Arte Moderna, surgia o binômio destruição/construção: derrubar o atraso artístico vigente para elaborar uma nova arte, marcada desde seu início por questões brasileiras². Não se pode esquecer que Mário jamais viajou à Europa: seu contato com as vanguardas foi significativamente mediado por teorias de um segundo momento histórico.

Uma questão que poderia ser abordada é o que Mário recebeu, no diálogo com os artistas brasileiros que estavam em Paris nos anos 1920. As escolhas destes, tanto de professores propriamente ditos como de modelos a serem seguidos e as conseqüentes pinturas eesculturas que criaram, bem como o que narravam a respeito do ambiente artístico e as idéias que formulavam em suas cartas, foram provavelmente, para o crítico, fontes de informação e reflexão mais importantes do que se costuma pensar.

Os artistas brasileiros vincularam experimentação e "leis eternas", internacionalização e nacionalismos, desconstrução das formas e figuração estilizada, planaridade e espaço perspectivo. É significativo que, em várias obras modernistas, ocorram efeitos de "colagens" entre formas modernas e tradicionais, gerando sentidos contraditórios. Também é digno de nota que, sendo os nacionalismos propugnados como valor na arte, eles se sentissem encorajados a recorrer a formas, cores e/ou temáticas oriundas da arte indígena, como em Rego Monteiro, ou dos tipos raciais e das cenas que evocavam uma realidade popular brasileira, como em Di Cavalcanti e em Tarsila na fase PauBrasil. Mas, ainda nesse caso, não se pode esquecer que o recurso a formas "outras", oriundas de outras culturas ou do passado remoto, serviu de motor para vários movimentos de vanguarda, com o que se pode avançar a hipótese de que também a motivação para recorrer a esses signos foi legitimada por essas fontes duplas.

O livro de Tadeu Chiarelli analisa em parte essas questões, sempre a partir dos escritos, conceitos e opiniões de Mário de Andrade. Os textos sobre arte, bem como a extensa correspondência trocada com missivistas tão significativos quanto os artistas Anita Malfatti, Tarsila do Amaral e Candido Portinari, e os poetas e escritores Manuel Bandeira, Carlos Drummond de Andrade e Pedro Nava, entre outros, são analisados sob todos os aspectos referentes às artes visuais. $\mathrm{O}$ autor também confronta algumas obras de ficção de Mário aos textos críticos, tentando encontrar os fios condutores de seu pensamento.

Pintura não ésóbeleza é o resultado da pesquisa de Tadeu Chiarelli para a tese de doutorado e objetiva analisar e avaliar o papel específico de Mário de Andrade como crítico de arte, proposta semelhante à da publicação anterior sobre Monteiro Lobato ${ }^{3}$ que corres pondia à sua dissertação de mestrado. Os dois livros evidenciam a pesquisa extremamente ampla e cuidadosa realizada nas duas ocasiões, bem como a análise aprofundada dos dados coligidos e a defesa de hipó-
[2] Klaxon, mensário de arte moderna. Introdução de Mário da Silva Brito. São Paulo: Livraria Martins Editora/Secretaria da Cultura, Ciência e Tecnologia do Estado de São Paulo, 1976 (edição fac-símile).
[3] Chiarelli, Tadeu. Um jeca nos vernissages: Monteiro Lobato e o desejo de uma arte nacional no Brasil. São Paulo: Edusp, 1995 
teses originais e necessárias para a real compreensão do papel que os críticos desempenharam, para além dos clichês facilmente apropriados e repetidos. Além disso, ambos os textos se interrelacionam. O autor declara, na introdução de Pintura não ésó beleza, que o livro foi elaborado a partir de uma reflexão a três: ele próprio, Mário de Andrade e... Monteiro Lobato. Constata-se, ao longo da leitura, a pertinência dessa declaração. Se a publicação anterior resgatava a crítica de Lobato para além do ataque a Anita Malfatti, evidenciando a coerência de sua trajetória e as linhas mestras de seu pensamento, o livro sobre Mário evidencia o caminhar reflexivo deste, desvelando, por trás do clichê que o apresenta unicamente como crítico modernista e oposto a Lobato, as idéias e conceitos presentes desde o início de sua trajetória, que foram se definindo ao longo do tempo e que acabaram por aproximá-lo, de forma até agora não analisada, de seu opositor.

Chiarelli tenta compreender em profundidade a trajetória do pensamento de Mário, que foi se evidenciando com seus desencantos, suas esperanças, seus equívocos e arrependimentos. E, também, o percurso de sua obra, com os caminhos trilhados ao longo do tempo. Chega, assim, ao que apresenta como cerne do pensamento do crítico: a existência de um "gênio brasileiro", segundo as palavras do autor, cujas raízes estariam na arte colonial, sobretudo na obra de Aleijadinho, e no século XIX na pintura de Almeida Júnior, considerado superior a todos os outros artistas brasileiros dos anos 1800 . No entanto, se tal gênio fora esboçado na arte do passado, chegara ao século XX em estado de incompletude. Se os primeiros modernistas haviam logrado atingi-lo em certos momentos precisos, como Tarsila em suas pinturas da fase Pau-Brasil, ele ainda esperava, contudo, por um grande artista e uma grande obra capazes de personificá-lo inteiramente. Esse papel caberia a Candido Portinari.

O que configuraria esse "gênio brasileiro"? Segundo Chiarelli, para Mário a obra de arte brasileira deveria ser de fundamentação clássica, sem perder o contato com a realidade, e deveria se basear no realismo e naturalismo do século XIX. Esses seriam comprometimentos da sua estética. Ao mesmo tempo, deveria apresentar indicações de uma visualidade brasileira, na qual destacava como exemplo o "mau gosto" das cores na palheta de Almeida Júnior, que fora transmitido às obras de Tarsila e outros modernistas, chegando finalmente às pinturas de Portinari.

O autor aponta a contradição existente no cerne desse pensamento crítico: a procura de uma arte atemporal, "incontaminada pelas circunstâncias históricas e fugidias das vanguardas", consideradas por Mário como puramente instrumentais, e ao mesmo tempo, "impregnada pelo desejo de fixação de um topos" (p.3o). 
Tempo e lugar imóveis, recurso a estilos do passado, criação a posteriori de uma linha genealógica para a visualidade brasileira, com vistas à inserção da arte do presente em uma "tradição" nacional: as relações entre o "gênio brasileiro" e os aspectos de retorno à ordem que o nutriram intelectualmente são, certamente, mais profundas e complexas do que as analisadas até o presente momento, mesmo neste livro que penetra tão profundamente no de pensamento Mário de Andrade.

O livro traz, no entanto, várias questões importantes para o esclarecimento dessas relações. Aponta como Mário reconheceu, em 1942, que o modernismo significou "a atualização da inteligência artística brasileira", mas não deixa de sublinhar que se tratou de uma atualização conservadora (p.31). Assinala também, em vários momentos, que ele sempre encarou as vanguardas de modo instrumental, considerando que delas não se deveria aproveitar mais do que alguns estilemas. Para Mário, as vanguardas teriam significado nada mais, nada menos do que uma etapa dentro de uma continuidade que unia passado e presente. Do mesmo modo, em seu livro Tadeu Chiarelli vincula a defesa que Mário fez de uma "visualidade brasileira", presente desde a constituição do país, à revalorização das formas de arte características e tradicionais de cada nação realizada pelos movimentos vanguardistas.

Todos esses elementos foram cuidadosamente extraídos da produção crítica de Mário ao longo de toda sua atuação nessa área, e contrapostos permanentemente às idéias e aos movimentos europeus do período. O autor confrontou-os com as opiniões expressas por Mário sobre obras de artistas europeus que teve a oportunidade de conhecer aqui no Brasil, algumas das quais adquiriu através de amigos. Isso pressupôs, também, uma extensa pesquisa da sua coleção de obras, entre as quais procurou destacar as linhas mestras, vinculando as escolhas às idéias estéticas expressas. Tadeu Chiarelli tentou, também, preencher as lacunas presentes nas críticas de Mário. Um exemploé sua hipótese sobre a fase da obra de Picasso à qual este, em seus textos, relacionava as obras de Portinari.

Chiarelli fundamenta seu estudo com praticamente todas as análises realizadas sobre as idéias estéticas de Mário, sobre as leituras que fez, as opiniões que emitiu, e também sobre a produção deste em outras áreas artísticas, como a música e a literatura.

O cotejo entre a atividade crítica e algumas criações literárias, sobretudoMacunaíma (1928), poderia ter evidenciado, no entanto, certas contradições essenciais, principalmente o descompasso entre os aspectos conservadores da primeira e a elaboração de uma obra literária moderna. Certas lacunas viriamà tona, como o silêncio de Mário sobre as telas $A b a$ poru eAntropofagia, que Tarsila pintou em 1928 e 1929, respectivamente, eos processos similares de metamorfoses e substituições do corpo existentes nessas telas e no livro que Mário não quis ou não pôde ver. Do mesmo modo, o caráter visual, cromático, que marca certas passagens 
dessa produção literária, demonstra que houve um diálogo de mão dupla entre escrita e pintura que ainda não foi analisado em profundidade eque se evidencia também nas semelhanças entre certas questões plásticas das obras dos artistas e de suas tomadas de posição e a tensão entre tradição e modernidade presente na crítica de Mário.

Teria sido também interessante abordar o papel que Oswald de Andrade desempenhou junto ao crítico nos primeiros tempos do modernismo, bem como as discordâncias e polêmicas progressivas entre os dois, que indicam em parte as diferenças nos posicionamentos estéticos de ambos.

A hipótese da procura de um "gênio brasileiro" na arte é original e comprova-se ao longo da leitura, mas a apresentação dessa proposta conceitual como equivalente a uma arte nacional poderia ser discutida, mesmo que, para Mário, essas questões se confundissem. Seria enriquecedor para o debate considerar tal equivalência a partir do pensamento de hoje e analisar o que evidenciaria no pensamento do crítico.

Apesar dessas lacunas, quase inevitáveis em um trabalho de pesquisa de tal porte e abrangência, pode-se dizer que pela primeira vez é apresentada ao público, tanto de especialistas como de apreciadores de Mário e das problemáticas do pensamento sobre arte no Brasil, uma análise de tal profundidade. Mário de Andrade nos é apresentado em toda a sua trajetória, com suas hesitações, suas voltas para trás, suas repetições e lacunas, e também com seus avanços e a extraordinária coerência quanto às linhas mestras de seu pensamento.

Além disso, vemos um autor para além do mito, com a plena consciência de seu papelúnico na história do pensamento brasileiro, mas com suas desilusões quanto ao reconhecimentoem suaépoca. Seu desengano quanto aos rumos da sociedade e da política no país, sua amargura quanto ao próprio modernismo e suas dúvidas quanto aos rumos da arte conviviam no fim de sua vida com a crença na "totalidade" que Portinari atingira num certo período ao ligar a arte à terra e ao povo brasileiros.

O livro subdivide-se em doze capítulos. Começa significativamente comos títulos "O círculo se abre" e "O círculo se expande", e conclui com "O círculo se constringe" e "O círculo se fecha". Não mostra, no entanto, o eterno retorno às mesmas idéias, mas a constituição dos fios condutores de um pensamento original, elaborado na confrontação analítica com as obras. A contribuição de Mário de Andrade à reflexão sobre arte brasileira, com seus limites, mas também com extrema sensibilidade visual e detecção de problemáticas que se apresentavam na fisicalidade mesma das obras, é aqui analisada com agudeza e profundidade, o que torna o livro de Tadeu Chiarelli uma obra de referência para a história e a análise das idéias estéticas e da crítica de arte no Brasil. 